\title{
Residual Deflections and Stresses in a Thick T-Joint Plate Structure
}

\section{Adak $\mathbf{M}^{1 *}$ and Soares $\mathbf{C G}^{2}$}

${ }^{1}$ Department of Applied Mathematics, Yeshwantrao Chavan College of Engineering, Nagpur-441110, Maharashtra, India

${ }^{2}$ Centre for Marine Technology and Engineering (CENTEC), Technical University of Lisbon, Instituto Superior Técnico, Lisbon, Portugal

\begin{abstract}
In this paper transient thermo-elastic-plastic problem of a thick rectangular T-joint fillet weld plates is solved numerically in which we need to determine the temperature distribution, thermal deflections and stresses when the boundary conditions are known. At the T-joint section (weld pool area) high constant temperature is considered initially and convection boundary conditions are applied at other three edges as well as top and bottom surface of the plate. T-joint section and vertical plate is fixed (case 1) for plate stability, only T-joint section is fixed (case 2) as a boundary constraint for stress analysis. Numerical technique (Finite element method, Ansys software) is used to obtain the solution of the boundary value problem.
\end{abstract}

Keywords: Thermo-elastic-plastic analysis; Transient temperature distribution; Residual deflection; Residual stress; Finite element method

\section{Introduction}

When a material is heated with initial high temperature in a weld joint (T-joint section), the highly localized transient heat and strongly nonlinear temperature fields in both heating and cooling processes cause non-uniform thermal expansion and contraction and thus result in plastic deformation in the weld and surrounding areas. Here T-joint corner section (initially temperature is applied) of the plate can be assumed to be fixed to reduce the deformation and induces stress due to fixed constraint. For the stress analysis different boundary constraints are considered in the present study.

T-joint fillet welds are extensively used in construction, shipbuilding, steel bridges and supporting frames for pressure vessels and piping, etc. Residual deformation can occur near the T-joint and base metal due to localize heating and subsequent rapid cooling by welding process. The accurate prediction of welding distortions is extremely difficult because of thermal and mechanical conditions created during the welding process including locally high temperatures, temperature dependent material properties and heat source model.

In this study, two thick rectangular plates with same dimension are considered for welding process at $\mathrm{T}$ joint section. Due to simplifying heat source model and time consuming, initially high temperature is considered at T-joint section. To analyze the thermo-mechanical problem convection boundary conditions at all free edges of both plates and top, bottom surface and temperature dependent material properties, Tables 1-5 are considered. Numerical technique Finite element method through ANSYS software [1] is used to obtain the temperature distribution, residual deformation and stresses after heattransfer at cooling stage.

The research activity in welding simulation started decades ago. Rosenthal [2] was among the first researchers to develop an analytical solution of heat flow during welding based on conduction heat transfer for predicting the shape of the weld pool for two and three dimensional welds. Some researcher have also developed the thermal finite element simulation to investigate the temperature distribution of a metal such as Kamala and Goldak [3], Nguyen et al. [4], Tekriwal and Muzumder [5], Yeung, and Thornton [6], and Bonifaz [7].

Over the past few years, finite element methods are used to predict distortion and residual stresses due to welding operations such as the studies by Friedman [8], Brown and Song [9], Mechaleris and Debiccari [10].

The effect of welding parameters, welding sequence, and welding joint geometry like butt joint, T-joint, corner joint is very important. Tsai and Cheng [11] investigated the distortion mechanism and the effects of welding sequence on thin panel distortions using a finite element analysis approach. Teng et al. [12] investigated the residual stresses and distortion of $\mathrm{T}$-joint fillet welds using $2 \mathrm{D}$ finite element

\begin{tabular}{|c|c|}
\hline${ }^{\circ} \mathbf{C}$ & $\mathbf{K g} / \mathbf{m}^{\mathbf{3}}$ \\
\hline 25 & 7800 \\
\hline 1450 & 7438 \\
\hline 3000 & 7438 \\
\hline
\end{tabular}

Table 1: Steel density versus temperature.

\begin{tabular}{|c|c|}
\hline${ }^{\circ} \mathbf{C}$ & $\mathbf{W} / \mathbf{m}^{\circ} \mathbf{C}$ \\
\hline 25 & 55 \\
\hline 750 & 29 \\
\hline 800 & 25.4 \\
\hline 1450 & 31 \\
\hline 3000 & 31 \\
\hline
\end{tabular}

Table 2: Steel thermal conductivity versus temperature.

\begin{tabular}{|c|c|}
\hline${ }^{\circ} \mathbf{C}$ & $\mathbf{J} / \mathbf{k g}\left({ }^{\circ} \mathbf{C}\right)$ \\
\hline 25 & 388 \\
\hline 700 & 894 \\
\hline 740 & 1234 \\
\hline 860 & 610 \\
\hline 1450 & 814 \\
\hline 3000 & 814 \\
\hline
\end{tabular}

Table 3: Steel specific heat versus temperature.

*Corresponding author: Adak M, Department of Applied Mathematics, Yeshwantrao Chavan College of Engineering, Nagpur-441110, Maharashtra, India, Tel: +91-8793435532; E-mail: malabikaadak@yahoo.co.in

Received September 12, 2016; Accepted October 03, 2016; Published October 06, 2016

Citation: Adak M, Soares CG (2016) Residual Deflections and Stresses in a Thick T-Joint Plate Structure. J Appl Mech Eng 5: 233. doi: 10.4172/2168-9873.1000233

Copyright: @ 2016 Adak M, et al. This is an open-access article distributed under the terms of the Creative Commons Attribution License, which permits unrestricted use, distribution, and reproduction in any medium, provided the original author and source are credited. 


\begin{tabular}{|c|c|}
\hline${ }^{\circ} \mathbf{C}$ & $\left(\mathbf{1 0 - 6} /{ }^{\circ} \mathbf{C}\right)$ \\
\hline 25 & 12 \\
\hline 1450 & 14 \\
\hline 3000 & 14 \\
\hline
\end{tabular}

Table 4: Thermal expansion of steel versus temperature.

\begin{tabular}{|c|c|c|}
\hline${ }^{\circ} \mathbf{C}$ & $\mathbf{G P a}$ & - \\
\hline 25 & 206 & 0.296 \\
\hline 100 & 203 & 0.311 \\
\hline 200 & 201 & 0.330 \\
\hline 300 & 200 & 0.349 \\
\hline 400 & 165 & 0.367 \\
\hline 500 & 100 & 0.385 \\
\hline 600 & 60 & 0.405 \\
\hline 700 & 40 & 0.423 \\
\hline 800 & 30 & 0.442 \\
\hline 900 & 20 & 0.461 \\
\hline 1000 & 10 & 0.480 \\
\hline 3000 & 10 & 0.480 \\
\hline
\end{tabular}

Table 5: Elastic modulus and Poisson's ratio of steel versus temperature.

analyses approach. Tsai and Jung [13], Chang and Lee [14], Chang et al. [15] and Biswas et al. [16] modeled the angular distortion of T-joints using a plasticity-based distortion welding with fillet welds.

Adak et al. $[17,18]$ obtained the stress analysis and residual deflection shape due to different boundary constraints in weld induced thick rectangular plate with finite element method. Guangming et al. [19] also studied effect of boundary conditions on residual stress and distortion in T-joint welds. Guoxiang et al. [20], Asifa et al. [21], Keivani et al. [22], Reenal et al. [23] predicted the residual stress and welding deformation in butt-weld joint for different clamped position on the plates.

It is clear from literature review that a large number of models exist to predict temperature distributions, residual stresses, and distortions in the welded joints, though most of them have concentrated on 2D problem and different boundary conditions as well as different parameters. In this study, 3D simulation process is needed with convection boundary conditions and high temperature dependent material properties for thermal analysis as well as suitable boundary conditions (cases 1 and 2) to predict welding deformation shape and stresses. That type of work is not done previously.

\section{Verification of Butt-Welding Analysis using Finite Ele- ment Analysis}

In this study, no experimental data are available to verify the simulation results and thus the results of the simulation are compared to numerical results obtained in a previous research. After validating the simulation results with the numerical results, the same finite element modeling is used to simulate the welding process through out this study.

A finite element simulation of a simple butt-joint welding for $3 \mathrm{D}$ model is verified comparing with the work of Long et al. [24]. To do this, a simple butt joint welding whose welding parameters are consistent to those of Long's model was simulated by using the ANSYS finite element code. The model then is verified by comparison of its temperature distribution at some chosen nodes with the Long's model. The temperature dependent material properties for the thermal and mechanical analyses were equivalent to those used in Long's analyses. Plate geometry of the butt-joint welding is similar to the Long's model.
The results show that the temperature histories at various locations from the weld line are in reasonable agreement with the result obtained by Long [24]. The peak temperatures for both models are almost identical. The distances from the weld line of the verification model are slightly different from Long's possibly due to mesh size. Figures 1 and 2 show the temperature distribution curves from Long's and verification models, respectively.

In the present study T-joint plate structure type of model and same procedure have been followed which are described in below.

\section{Problem Formulation}

\section{Thermal analysis}

The conduction heating of the solid with constant temperature source at the fixed end is considered to simulate the welding process for 2-D problem reported by Sunar et al. [25]. Here, the 3D transient heat conduction equation for a thick rectangular $\mathrm{T}$-joint plate heated at T-joint section is written as:

$$
\rho C \frac{\partial T}{\partial t}=\frac{\partial}{\partial x}\left(k_{x} \frac{\partial T}{\partial x}\right)+\frac{\partial}{\partial y}\left(k_{y} \frac{\partial T}{\partial y}\right)+\frac{\partial}{\partial z}\left(k_{z} \frac{\partial T}{\partial z}\right)
$$

where $\rho, C$ and $k$ are density, specific heat and thermal conductivity depends on temperature respectively.

Subject to the initial and boundary conditions in both horizontal and vertical plates:

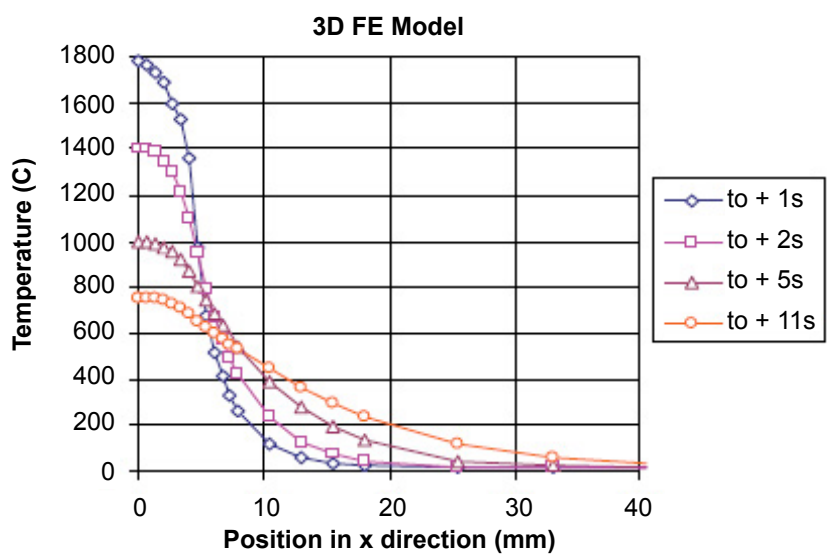

Figure 1: Temperature along transverse direction (x-axis) from Long (2009).

3D FE Model

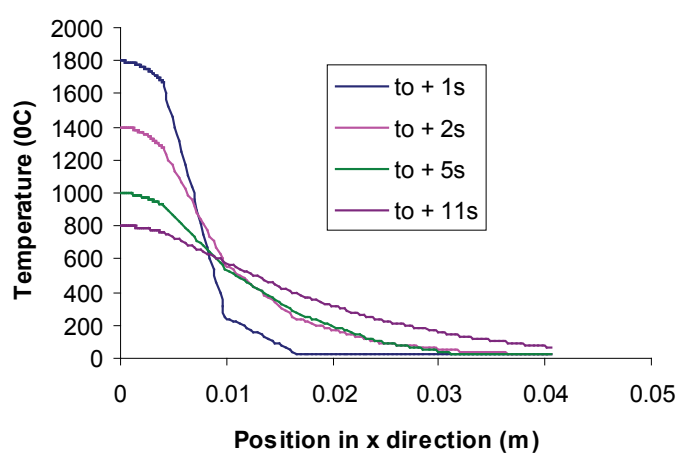

Figure 2: Temperature along transverse direction ( $\mathrm{x}$-axis) calculated here. 
$\mathrm{T}(\mathrm{x}, \mathrm{y}, \mathrm{z}, 0)=\mathrm{T}_{0}$ (ambient temperature).

At whole plate except T-joint section.

$\mathrm{T}(\mathrm{x}, \mathrm{y}, \mathrm{z}, 0)=\mathrm{T}_{1}$ (fixed high temperature for weld pool at $\mathrm{T}$ joint) $(3)$

At the free surface except in the weld pool of the rectangular plate (Figure 3), convection boundary conditions are considered at horizontal and vertical plate. Therefore,

On the surface along the $\mathrm{x}$ axis and parallel to $\mathrm{x}$ axis,

$k_{z} \frac{\partial T(x, y, z, t)}{\partial z}=h\left[T(x, y, z, t)-T_{a m b}\right]$

On the surface parallel to $\mathrm{z}$ axis,

$k_{x} \frac{\partial T(x, y, z, t)}{\partial x}=h\left[T(x, y, z, t)-T_{a m b}\right]$

On the surface top and bottom surface,

$k_{y} \frac{\partial T(x, y, z, t)}{\partial y}=h\left[T(x, y, z, t)-T_{a m b}\right]$

where $\mathrm{h}$ is the convection coefficient.

The heat exchange between the welded plate and its surroundings during welding and subsequently, cooling takes place by both convection and radiation. In the thermal model the convection coefficient $\mathrm{h}=15 \mathrm{~W} \mathrm{~m}^{-2}$, emissivity $\varepsilon=0.9$ and the Stefan-Boltzmann constant $=5.669 \times 10^{-8} \mathrm{~W} \mathrm{~m}^{-2} \mathrm{C}^{-4}$ are considered by Long et al. [15].

\section{Mechanical Analysis}

Due to highly localized temperature at $\mathrm{T}$-joint section as a weld pool, a very large temperature variation occurs over a small region. Consequently, considerable thermal stresses are generated due to the thermal gradient.

The thermal elasto-plastic material model based on the von Mises yield criterion and the isotropic strain hardening rule is considered. Stress-strain relations can be written as

$$
\begin{aligned}
& {[\sigma]=[\mathrm{D}]\left[\varepsilon^{e}\right]} \\
& {[D]=\left[\mathrm{D}^{\mathrm{e}}\right]+\left[\mathrm{D}^{\mathrm{p}}\right]}
\end{aligned}
$$

and

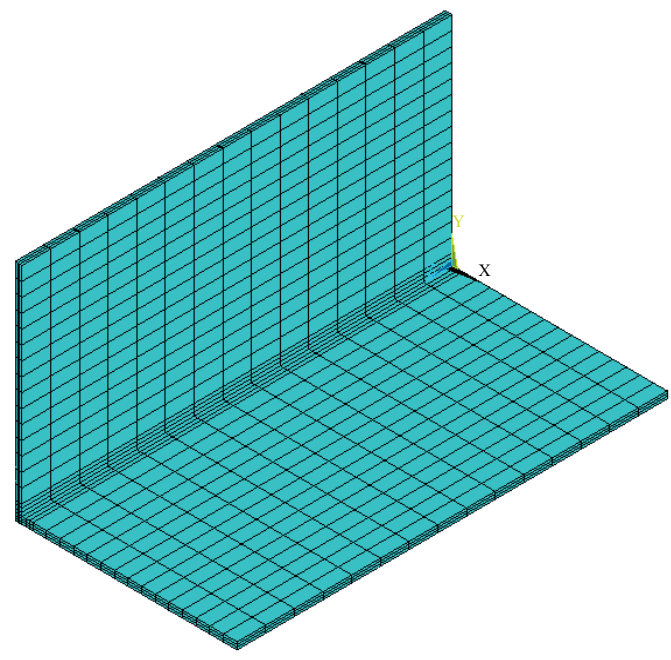

Figure 3: Finite element model of T-joint plates.

\section{$\left[\varepsilon^{e}\right]=[\varepsilon]-\left[\varepsilon^{t}\right]$}

Where $\left[D^{\mathrm{e}}\right]$ is the elastic stiffness matrix, $\left[\mathrm{D}^{\mathrm{p}}\right]$ is the plastic stiffness matrix and $[\varepsilon],\left[\varepsilon^{t}\right]$ are the total and thermal strain vectors respectively.

The above stress-strain relations can be written in Cartesian coordinates of $(\mathrm{x}, \mathrm{y}, \mathrm{z})$ as,

$$
\begin{aligned}
& \varepsilon_{x x}=\left(\frac{1}{E}\right)\left[\sigma_{x x}-v \sigma_{y y}\right]+\alpha \Delta T(x, y, z, t) \\
& \varepsilon_{y y}=\left(\frac{1}{E}\right)\left[\sigma_{y y}-v \sigma_{z z}\right]+\alpha \Delta T(x, y, z, t) \\
& \varepsilon_{z z}=\left(\frac{1}{E}\right)\left[\sigma_{z z}-v \sigma_{x x}\right]+\alpha \Delta T(x, y, z, t) \\
& \gamma_{x y}=2(1+v) \frac{\tau_{x y}}{E} \\
& \gamma_{y z}=2(1+v) \frac{\tau_{y z}}{E} \\
& \gamma_{z x}=2(1+v) \frac{\tau_{z x}}{E}
\end{aligned}
$$

Where E, $v$ and $\alpha$ are the modulus of elasticity, Poisson's ratio and coefficient of thermal expansion, respectively. In the above equation, $\Delta \mathrm{T}(\mathrm{x}, \mathrm{y}, \mathrm{z}, \mathrm{t})$ represents the temperature rise at a point $(\mathrm{x}, \mathrm{y}, \mathrm{z})$ at time $=$ $\mathrm{t}$ with respect to that at $\mathrm{t}=0$ corresponding to a stress free condition.

Boundary conditions: T-joint section and vertical plate are fixed as a boundary constrain during heat transfer (case 1). Only T-joint section is fixed as a boundary constrain during heat transfer (case 2).

Due to above boundary conditions with different temperature at different point $(\mathrm{x}, \mathrm{y}, \mathrm{z})$, thermal deflection and stress field are investigated using FEM approach.

\section{Solution of the Problem}

Two rectangular plates with same dimension $100 \mathrm{~mm} \times 250 \mathrm{~mm} \times$ $6 \mathrm{~mm}$ (Figure 3) are consider for finite element modeling.

For thermal analysis, assume,

$T \approx \bar{T}=\sum_{i=1}^{r} N_{i} T_{i}=[N]\{T\}$

where $[\mathrm{N}]$ is the shape function.

Applying Galerkin criterion, the heat conduction equation (1) can be written to each element as follows:

$\int_{\mathrm{v}}\left[\mathrm{N}_{\mathrm{i}} \frac{\partial}{\partial \mathrm{x}}\left(\mathrm{k}_{\mathrm{x}} \frac{\partial \overline{\mathrm{T}}}{\partial \mathrm{x}}\right)+\mathrm{N}_{\mathrm{i}} \frac{\partial}{\partial \mathrm{y}}\left(\mathrm{k}_{\mathrm{y}} \frac{\partial \overline{\mathrm{T}}}{\partial \mathrm{y}}\right)+\mathrm{N}_{\mathrm{i}} \frac{\partial}{\partial \mathrm{z}}\left(\mathrm{k}_{\mathrm{z}} \frac{\partial \overline{\mathrm{T}}}{\partial \mathrm{z}}\right)\right] \mathrm{dxdydz}=\int_{\mathrm{v}} \mathrm{N}_{\mathrm{i}} \rho c \frac{\partial \overline{\mathrm{T}}}{\partial \mathrm{t}} \mathrm{dxdydz}$

Using by parts,

$$
\begin{gathered}
{\left[\mathrm{N}_{\mathrm{i}}\left(\mathrm{k}_{\mathrm{x}} \frac{\partial \overline{\mathrm{T}}}{\partial \mathrm{x}} \mathrm{l}\right)+\left(\mathrm{k}_{\mathrm{y}} \frac{\partial \overline{\mathrm{T}}}{\partial \mathrm{y}} \mathrm{m}\right)+\left(\mathrm{k}_{\mathrm{z}} \frac{\partial \overline{\mathrm{T}}}{\partial \mathrm{z}} \mathrm{n}\right)\right] \mathrm{dS}-} \\
\left.\int_{\mathrm{s}} \int_{\mathrm{v}}\left[\mathrm{k}_{\mathrm{x}} \frac{\partial[\mathrm{N}]}{\partial \mathrm{x}} \frac{\partial \mathrm{N}_{\mathrm{i}}}{\partial \mathrm{x}}+\mathrm{k}_{\mathrm{y}} \frac{\partial[\mathrm{N}]}{\partial \mathrm{y}} \frac{\partial \mathrm{N}_{\mathrm{i}}}{\partial \mathrm{y}}\right)+\mathrm{k}_{\mathrm{z}} \frac{\partial[\mathrm{N}]}{\partial \mathrm{z}} \frac{\partial \mathrm{N}_{\mathrm{i}}}{\partial \mathrm{z}}\right]\{\overline{\mathrm{T}}\} \mathrm{dxdydz}=0
\end{gathered}
$$

Using convection boundary conditions (2) - (6), final equation takes form as

$$
[C] \frac{d\{T\}}{d t}=[K]\{T\}
$$

Where, $[\mathrm{C}]$ is specific heat matrix, $[\mathrm{K}]$ is conductivity matrix, $\{\mathrm{T}\}$ is vector of nodal temperature, $d\{T\} / d t$ is vector of time derivative of $\{\mathrm{T}\}$. 


\section{Convergence and Stability Scheme}

The terms $\frac{d T}{d t}$ and $\mathrm{T}$ are written in various forms in different time stepping schemes.

$$
[\mathrm{C}]\left\{\frac{\mathrm{T}(\mathrm{t}+\Delta \mathrm{t})-\mathrm{T}(\mathrm{t})}{\Delta \mathrm{t}}\right\}=[\mathrm{K}]\{\theta \mathrm{T}(\mathrm{t}+\Delta \mathrm{t})+(1-\theta) \mathrm{T}(\mathrm{t})\}
$$

This analysis requires an integration of the heat conduction equation with respect to time. The Crank-Nicholson theta integration $(\theta=1 / 2)$ scheme is tested for convergence and stability.

\section{Material Properties}

In thermal-elastic-plastic analysis, temperature dependent material properties are used.

Steel grade AH36 (high strength shipbuilding steel) is implemented with temperature dependent on properties as specified in Tables 1-5 and Figure 4.

Bilinear Isotropic Hardening option was adopted and it uses the von Misses yield criteria coupled with an isotropic work hardening assumption shown in Figure 5. This option is often preferred for large strain analyses. The material behaviour is described by a bilinear stress-strain curve starting at the origin with positive stress and strain values. The initial slope of the curve is taken as the elastic modulus of the material. At the specified yield stress, the curve continues along the second slope defined by the tangent modulus (having the same units as the elastic modulus). The tangent modulus can not be less than zero nor greater than the elastic modulus.

\section{Element Type}

For thermal analysis a 3D 8-node element (SOLID 70) with three degrees of freedom at each node (translations in the nodal $\mathrm{x}, \mathrm{y}$ and $\mathrm{z}$ directions) is used, and for structural analysis the element type is SOLID 185. The element has plasticity, creep, swelling, stress stiffening, large deflection, and large strain capacities. This choice was arrived at often a parametric study using different element types shown in Figure 6, which led to the conclusion that choosing an element having both thermal and structural characteristics is according to experience not optimal.

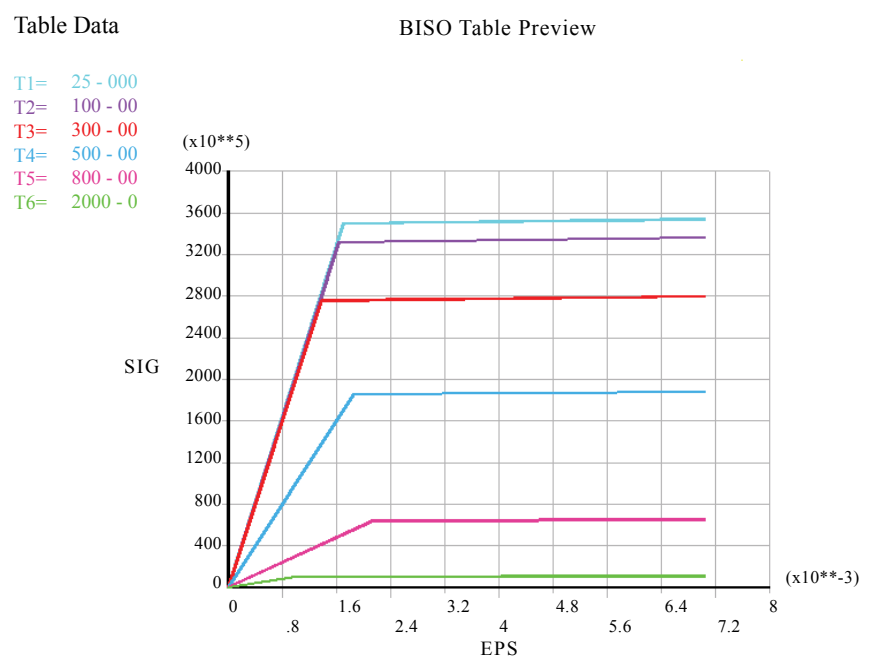

Figure 4: Stress- strain behavior of steel at different temperatures.

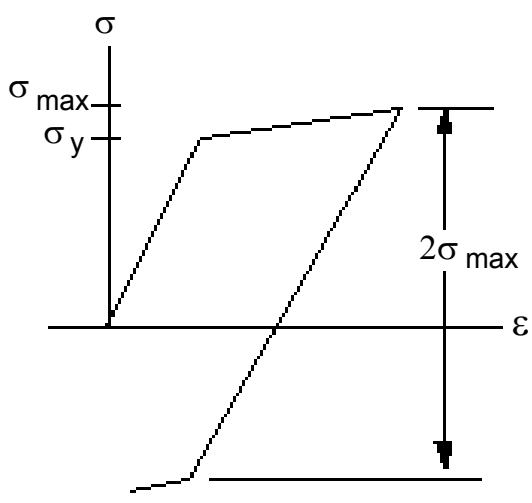

Figure 5: Bilinear isotropic hardening.
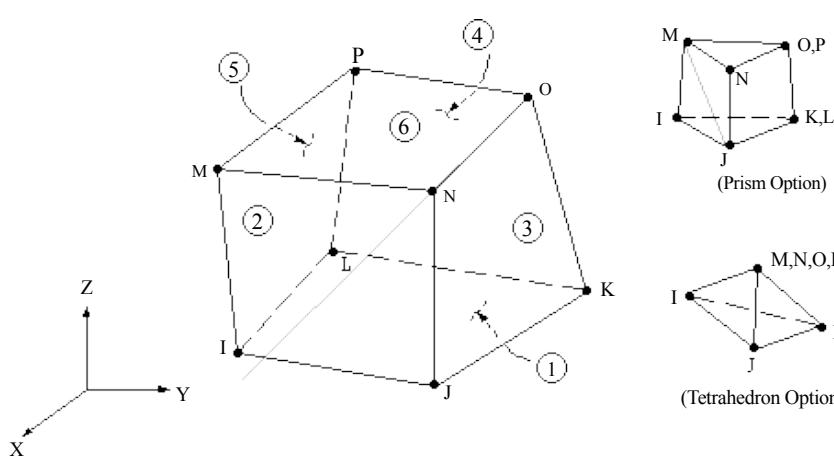

Figure 6: Element type.

\section{Mesh Generation}

In order to generate the system of equations, as well as to find the result at each point of the rectangular plate, a mesh is generated throughout the volume. In order to achieve this, the ANSYS program allows for control of the size and geometry of the mesh in order to obtain the most precise solution. However, a very large number of grid points can compromise the computer's capacity. Figure 7 shows the mesh in the symmetry half of the rectangular plate. Welding direction being $\mathrm{z}$-axis, sharp temperature gradients are expected along both $\mathrm{x}$ and y-axes. Therefore very fine grid has been adopted in the weld bead region; finer mesh grid has been chosen away from weld region and course grid is chosen along welding direction (z-axis).

\section{Birth and Death Feature}

The material deposition is modeled using an element "birth and death" technique. To achieve the death element effect, ANSYS code does not actually remove the element from the model. Instead, the weld elements are first deactivated by multiplying their stiffness by a huge reduction factor. Meanwhile, to obtain the birth element effect, the ANSYS program the reactivates the death element by allowing its stiffness, element load etc. return to their original values.

\section{Results and Discussion}

Numerical simulation is done for thermal analysis as well as mechanical analysis using equations (1)- (17). Temperature field at different heating periods are obtained numerically and corresponding deflection shape and stress fields are obtained using finite element method. 
Citation: Adak M, Soares CG (2016) Residual Deflections and Stresses in a Thick T-Joint Plate Structure. J Appl Mech Eng 5: 233. doi: 10.4172/21689873.1000233

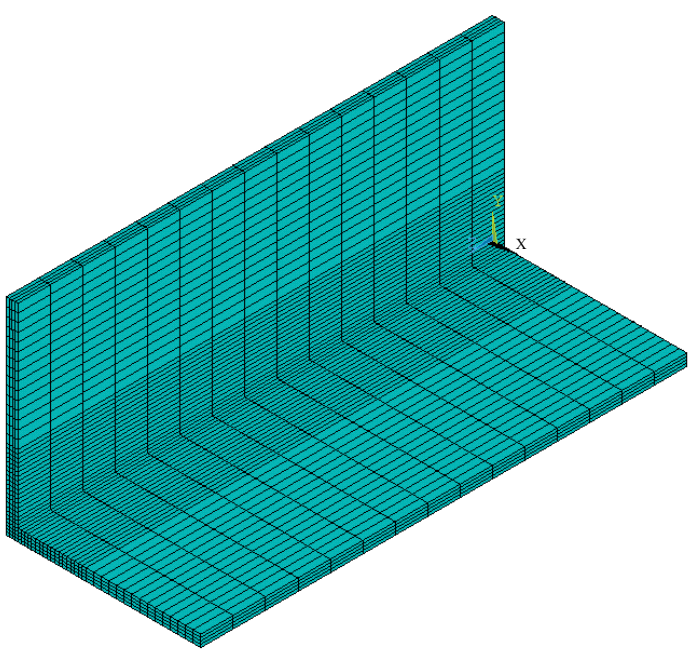

Figure 7: The mesh in the half of symmetry plate.

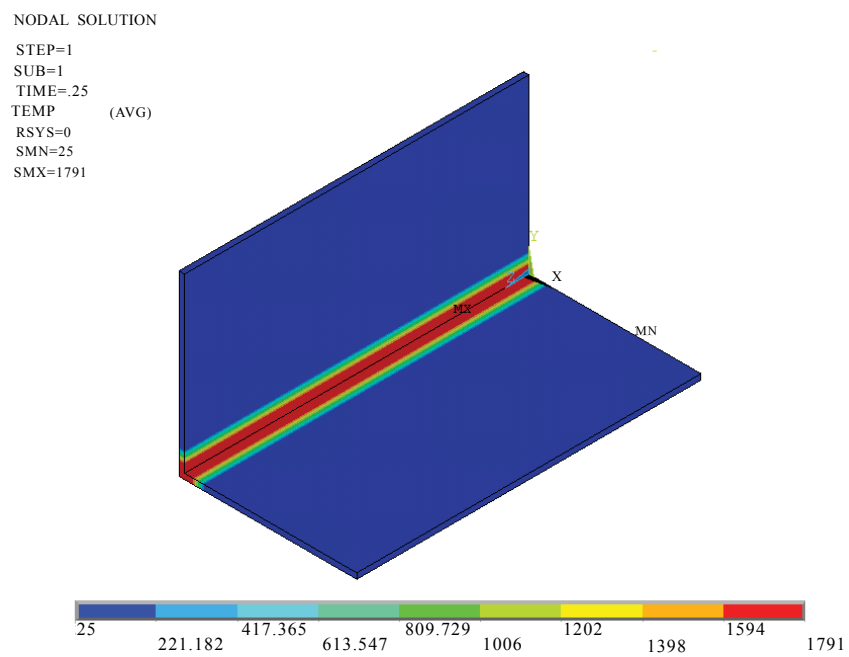

Figure 8: 3-D temperature distribution after $0.25 \mathrm{sec}$ during welding.

Figures 8 and 9 shows the temperature distribution in the rectangular T-joint plate for different heating periods. The decay of temperature profiles is sharp in the early heating period and as the heating period progresses, it becomes more gradual (Figure 2). As the time progress to $30 \mathrm{sec}$, temperature contours extend in the transverse direction ( $\mathrm{x}$ axis), while temperature distribution in the longitudinal direction (y axis) does not change.

Figure 2 shows the temperature distribution along transverse direction ( $\mathrm{x}$ axis) for different time periods and in heating zone, temperature is high, gradually temperature decrease.

Figure 10 shows the deformed shape after cooling process due to boundary condition (case 1). Significant bend-up residual distortion is observed. In this case, boundary conditions are applied in heating direction as well as in vertical plate, so residual distortion can be interpreted in horizontal plate.

As boundary constraint is applied along heating direction only (case 2), deformation shape is like Figure 11. In this case horizontal

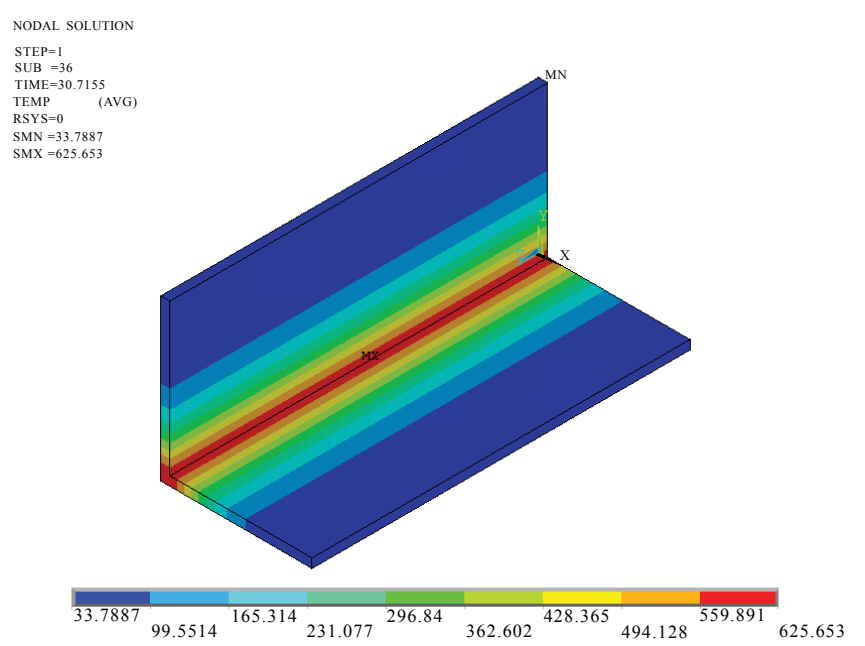

Figure 9: 3-D temperature distribution after $30 \mathrm{sec}$ during welding.

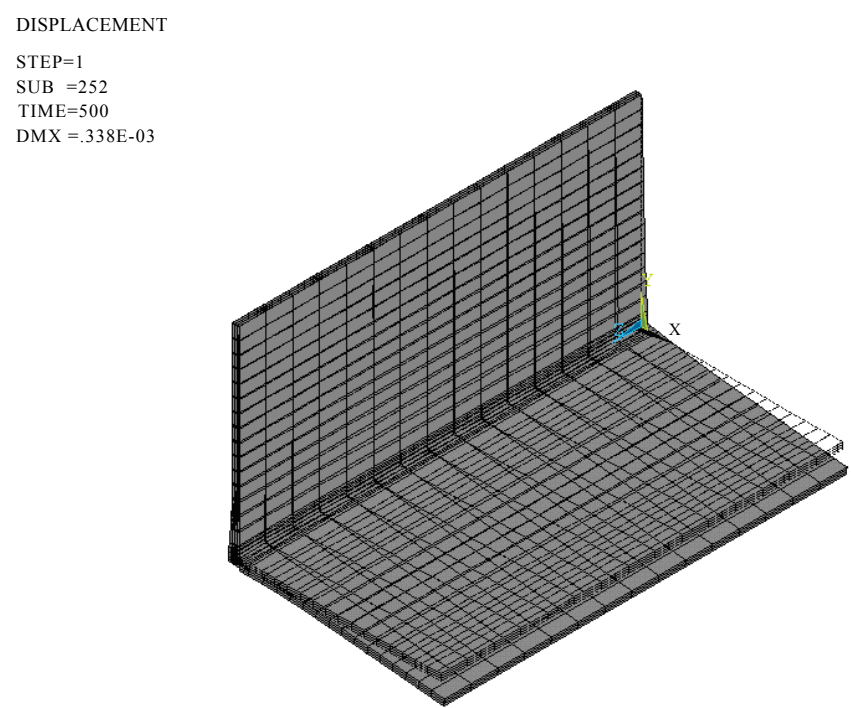

Figure 10: Deformed shape of the T-joint after welding.

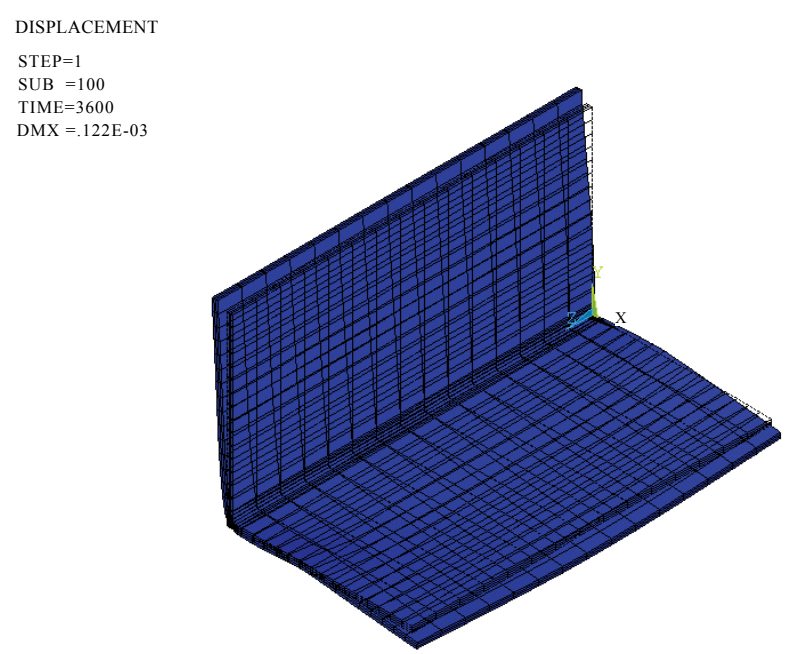

Figure 11: Final deformation shape for boundary constraint at welding line. 
Citation: Adak M, Soares CG (2016) Residual Deflections and Stresses in a Thick T-Joint Plate Structure. J Appl Mech Eng 5: 233. doi: 10.4172/21689873.1000233

plate as well as vertical plate both is deformed. So, boundary constraint is most effectible in residual deformation.

According to the $1^{\text {st }}$ boundary constraint end edge of the horizontal plate is free, so angular deformation is maximize at middle of the free edge of horizontal plate and very low at end points of the edge shown in Figure 12. Deformation at the control points perpendicular to the heating line at horizontal plate is observed in Figure 13. Here is also high deformation at end edge of plate (free edge).

Transverse stresses and longitudinal stresses are calculated by using

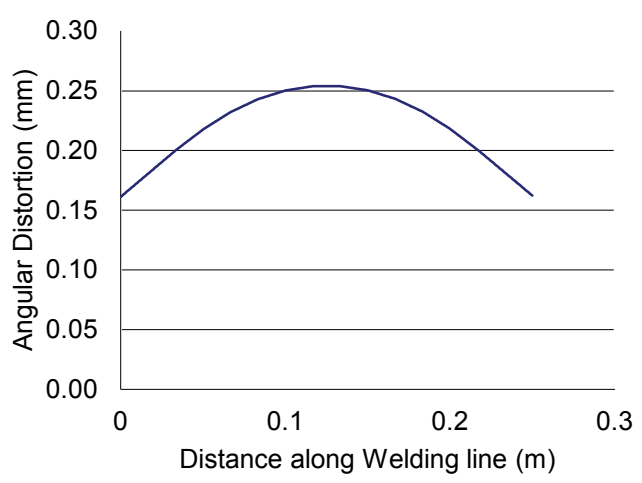

Figure 12: Angular distortion at the points of end edge.

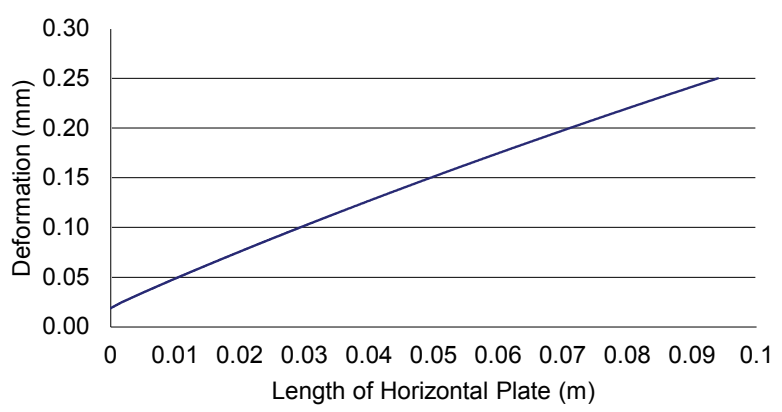

Figure 13: Deformation perpendicular to the heating line at horizontal plate parallel to heating line at horizontal plate.
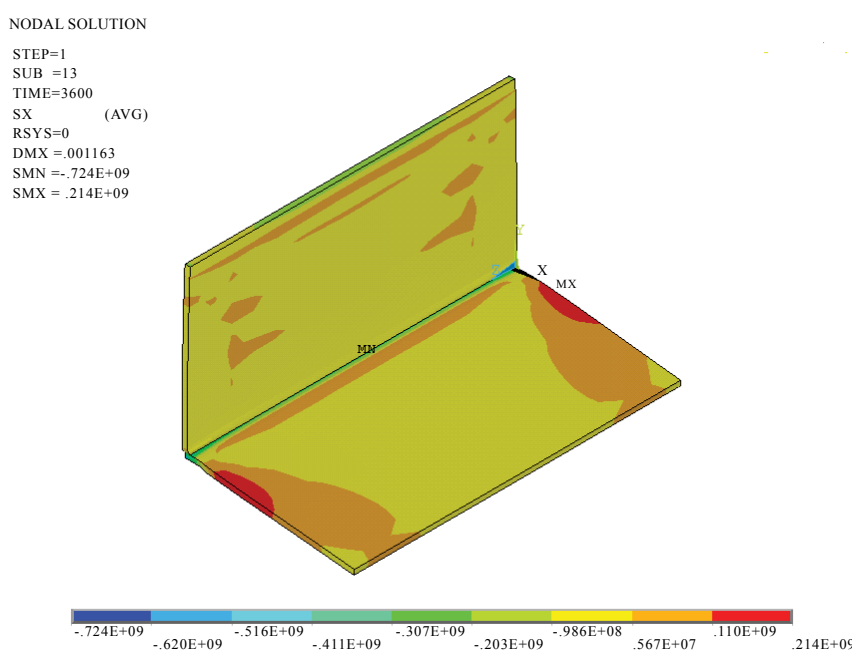

Figure 14: A view of the longitudinal stresses in $T$ joint plates.

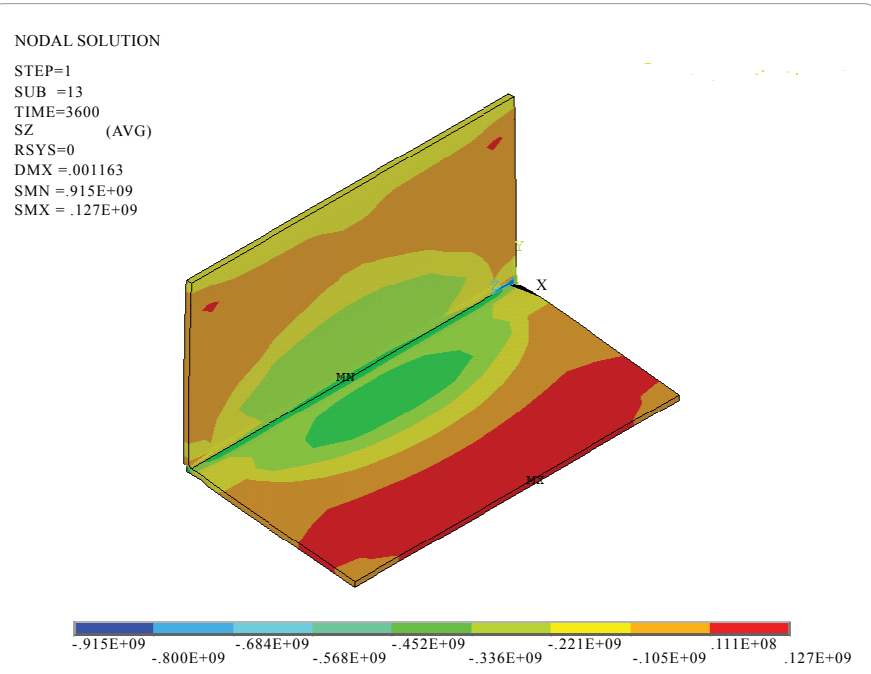

Figure 15: A view of the transverse stresses in $\mathrm{T}$ joint plates.

finite element method shown in Figures 14 and 15. From Figure 14, it is possible to identify regions where the residual stresses and deformation reached maximum value and can lead to damages in plate structure. The longitudinal stress component is more in the heat affected region. The maximum magnitude of Von-Mises stress is more than the yield strength of material.

\section{Overall Conclusions}

A thick rectangular T-joint plate structure with same dimension is considered for welding process with fixed high temperature at $\mathrm{T}$-joint section for simplifying heat source model. Results of the numerical analysis of temperature and stress field distribution in T-joint section, carried out by the finite element methods through ANSYS software. Two type of boundary conditions (cases 1 and 2) to reduce the deformation are applied in $\mathrm{T}$-joint fillet welded structure and final deformations pattern are obtained in Figures 9 and 10 as well as stress analyses are predicted. Results show that deformation is not very high and transverse and longitudinal stresses are not much more than yield strength in rectangular $\mathrm{T}$ joint plate structure.

\section{Acknowledgement}

This work has been made under the plurianual funding of the Portuguese Foundation of Science and Technology (Fundação para Ciência e Tecnologia) to the Centre for Marine Technology and Engineering (CENTEC).

\section{References}

1. Ansys Inc Theory reference Ansys Inc.

2. Rosenthal $D(1946)$ The theory of moving sources of heat and its application to metal treatments. Transactions of ASME 2 : 849-866

3. Kamala V, Goldak J (1993) Error due to two dimensional approximation in heat transfer analysis of welds. Welding Journal September 2: 440-446

4. Nguyen N, Ohta A, Matsouka K, Suzuki N, Maeda Y (1999) Analytical solutions for transient temperature of semi-infinite body subjected to $3 \mathrm{D}$ moving heat sources.Welding Journal August 9: 265-274

5. Tekriwal $P$, Mazumder $\mathrm{J}(1988)$ Finite element analysis of three-dimensiona transient heat transfer in GMA welding.Welding Research Supplement 2:150 $-156$

6. Yeung K, Thornton P (1999) Transient thermal analysis of spot welding electrodes. Welding Research Supplement.

7. Bonifaz E (2000) Finite element analysis of heat flow in single pass arc welds Welding Research Supplement 2: 121-125. 
Citation: Adak M, Soares CG (2016) Residual Deflections and Stresses in a Thick T-Joint Plate Structure. J Appl Mech Eng 5: 233. doi: 10.4172/21689873.1000233

8. Friedman E (1975) Thermo-mechanical analysis of the welding process using the finite element method. Transaction of the ASME 97: 206-213.

9. Brown S, Song H (1992) Finite element simulation of welding of large structure. $\mathrm{J}$ Engineering for Industry. 24: 441-451

10. Michaleris P, Debiccari A (1999) Prediction of welding distortion. Welding Journal. 2: $172-180$

11. Tsai CL, Cheng WT (1999) Welding distortion of thin plate panel structures. Welding Journal 156s-165s.

12. Teng TL, Fung CP, Chang PH, Yang WC (2001) Analysis of residual stresses and distortions in T-joint fillet welds. Int $\mathrm{J}$ Pressure Vessels and Piping 78: 523-538.

13. Tsai CL, Jung GH (2004) Plasticity-based distortion analysis for fillet welded thin plate T-joints. Welding Journal :177s-187s

14. Chang KH, Lee $\mathrm{CH}$, Jang GC, Park HC (2007) Behaviour of stresses in T-joint fillet welds under superimposed mechanical loading. Steel Structures 7: 311317 .

15. Chang $\mathrm{KH}$, Lee $\mathrm{CH}$ (2009) Finite element analysis of the residual stresses in T-joint fillet welds made of similar and dissimilar steels. Int JAdvanced Manufacturing Technology. 7: 250-258

16. Biswas P, Mahapatra MM, Mandal NR (2010) Numerical and experimental study on prediction of thermal history and residual deformation of double-sided fillet welding. J Engineering Manufacture 224:125-134.

17. Adak M, Mandal NR (2009) Pseudolinear equivalent constant rigidity concept for analyzing welding deformation. Applied Mathematical Modeling 33: 20962018.

18. Adak M, Guedes-Soares C (2002) Effects of different restraints on the weld induced residual deformations and stresses in a steel plate. Int J Advanced Manufacturing Technology 71: 699-710.

19. Guangming F, Marcelo IL, Menglan D, Segen FE (2014) Effect of boundary conditions on residual stress and distortion in T-joint welds. J constructional steel research 102: 121-135.

20. Guoxiang XU , Chuansong WU, Xuezhou MA, Xuyou WANG (2013) Numerical analysis of welding residual stress and distortion in laser + GMAW hybrid welding of aluminum alloy T-joint. Acta Metall Sin (Engl Lett) 26: 352-360.

21. Asifa K, Li Hong, Li Li, Shehzad K (2013) Prediction of welding deformation residual stresses in fillet welds using indirect couple field FE method. Research $\mathrm{J}$ of Applied Science Engineering and Technology 5: 2934-2940.

22. Keivani R, Jahazi M, Pham T, Khodabandeh AR, Afshar MR (2014) Predicting residual stresses and distortion during multisequence welding of large size structures using FEM. Int J Advanced Manufacturing Technology 73: 409-419.

23. Reenal RC, Soo K, Qian Wu Q, Bong-Yong K, Yeon Shim K (2014) Prediction of residual stress and welding deformation in butt-weld joint for different clamped position on the plates. Int $\mathrm{J}$ Engineering Science and Innovative Technology 3: 34-44.

24. Long H, Gery D, Carlier A, Maropoulos PG (2009) Prediction of welding distortion in butt joint of thin plates. Materials and Design 30: 4126-4135.

25. Sunar M, Yilbas BS, Boran K (2006) Thermal and stress analysis of a sheet metal in welding. $\mathrm{J}$ of Materials Proc Tech 172: 123-129. 